\title{
"Anxiety level of korfball player pre, during and post competition"
}

\author{
Pramod Sahadeorao Bhalerao \\ Associate Professor \\ Degree College of Physical Education, HVPM, Amravati
}

\begin{abstract}
The purpose of this study was to assess the anxiety level among the players of anxiety level of Korfball players pre, during and post of the competition, so the inter collegiate player of Korfball was selected for the study. 30 players were presented with the sport competitive anxiety test. The SCAT questionnaire form was distributed to each player at least one hour to 30 minutes for pre data, during the half time for the during data and after the match post data was collected and asked to answer the question then and there. The data collected was treated statistically by applying one way analysis of variance statistical technique (ANOVA). The level of significance difference, if any was set at 0.05 . The findings and result of the calculated data revealed that there was significant difference in the anxiety levels preduring-post of the competition
\end{abstract}

Keywords: Anxiety, Korfball, player, completion, competition, different levels

\section{Introduction}

Physical education scores as medium for men's total education intellectual development through experience, hence promotion of physical education and sports is the moral and social responsibility of each nation. The promotion of sports is no longer a dispute. The importance has been recognized at international level by all countries of the world. Today sport is considered as an International discipline because it belongs international understanding and universal brotherhood.

Psychology : Kamlesh $1^{1}$ says "Psychology is the science of the activities of an individual in relation to this environment." The activity of the Soul or the mind, in otherwards, the internal behaviour is manifested through the physical or the outer, for thinking and doing are points or the same stretch and are inseparable for the struggle of survival.

Importance of Psychology in sports:

Psychology of sports means applying psychological theories to aspects of sports, such as coaching and teaching. The sport psychology is concerned with analyzing human behavior in various types of performance.

Psychological variables :

Modern man lives in a stress world in which the important skill of success based on his psychological abilities. Behaviour can be defined as the total aggregate of human responses and that a person responds to work internal and external stimuli of the psychological component such as motivation, attitude, attention, anxiety, emotion etc.

Anxiety : Anxiety selected for the study, is one of the psychological factor. It differs from arousal in that it encompasses both, some degree of activation and an unpleasant emotional state. Thus anxiety is the term used to describe the combination of intensity of behaviour and direction of an impact or emotion. ${ }^{2}$

Importance of Anxiety in sport :

Anxiety plays an important role in the acquisition of motor skills as well as athletic performance. Anxiety can either increase or decrease in performance whether effect is positive or negative, it depends upon how an individual sportsman perceives the situation.

Keeping in view of all these facts the present investigator tries to find out the anxiety level of the Korfball player pre-during and post of competition.

Statement of the Problem :

Since anxiety is equated with fear practicing and completing sports persons irrespective of their sex and age, tend to have variety of fears at almost all stages of their sporting career, hence the research scholar has undertaken the study stated as "Anxiety level of Korfball player pre-during and post competition."

\section{Purpose of the study}

The main purpose of the study was to investigate "Anxiety level of Korfball player pre-during and post competition.

\section{Significance of the study}

The concept of studying different anxiety levels among players indicates the causes of build up of mixed emotions in the organism pre during and post competition. The result of the study have highlighted the anxiety level of the selected players and if needed proper counseling programmed may be

${ }^{1}$ L. Kamlesh, Psychology of Physical Education and Sports (Delhi Metropolitan Book Company Pvt. Ltd. 1983), P. 12

${ }^{2}$ AM Bird and B.K. Cripe, Psychological and sport Behaviour (St Louis : Times Mirror, Published 1986), P. 79 
devised to release or reduce anxiety levels, which may work not only as preventive measure but also as a curative measure.

Hypothesis :

On the basis of literature and discussion with experts as well as the research scholars own understanding, it was hypothesized that there may be significant difference of anxiety level among Korfball player pre during post of competition.

\section{Delimitations :}

The present study was delimited to the following aspects :

1) Only male players belonging to Korfball from the intercollegiate tournament of SGB Amravati University.

2) The age of the selected subject ranged from 18-25 years.

3) 30 players were selected for the following study.

4) Appropriate as well as feasible questionnaire (SCAT) was used to collect necessary data.

\section{Limitation :}

1) The researcher had no control over the prevailing circumstances and the existing mental and physical condition of the subject at the time of administering the questionnaire, which might affect the result of the study, was considered a major limitation.

2) No motivational technique was adopted while collecting the data.

\section{Definations:}

Anxiety : A feeling of worry or fear, especially about the future.

Stress : Worry and pressure that is caused by having too much to deal with.

Tension : State of being restless, mentally and physically.

Pre-competition : It is the time period, one hour prior to participate in competition.

During competition : It is time period during the competition.

Post competition : After game period the time of rest is post of competition.

Review of literature

Radha $^{3}$ conducted a study on psychological factors and soccer performance of South Indian University players. In this study, psychological factors, namely competition and psychology were studied in relation to soccer playing ability. Accordingly 100 university soccer players from Tamilnadu, Karnataka, Kerala and Andhra Pradesh were selected. Sport competition Anxiety Test (SCAT) questionnaire developed by R. Martens to measure anxiety was adopted.

The obtained factors on the psychological factor were correlated with Soccer playing ability using Pearson's Product Moment correlation and partial correlation to eliminate the influence of the third variable, aggression. It is traced from the result that there was a negative correlation between playing ability and anxiety. Somehow, aggressiveness was highly correlated with Soccer playing ability at a significant level. The result of this study revealed that moderate level of anxiety was more pleasant among the South Indian University players.

Parthiban $^{4}$ conducted a study on selected psychological factors as determinants for the basketball performance among male intercollegiate basketball players, psychological variables such as motivation, anxiety, aggression and personality factors were studied.

The questionnaire were used to collect the data, motivation, anxiety test (SCAT) developed by R. Marten's aggression was assessed through containing four statements administered to find out the specific type of aggressive behavior in competitive games and sports, personality was assessed through the Eysenck's Reliability inventory. The result of this study showed that the psychological factors were significantly related to basketball playing ability of inter collegiate level. Anxiety was significantly correlated with the basketball performance. Aggression had shown significant relationship with basketball playing ability.

Kanji ${ }^{\mathbf{5}}$ studied antigenic training reduces anxiety after coronary angioplasty, A random clinical trial Antigenic training (AT) is the method of auto suggestion with the potential for reducing anxiety. This study tests whether AT lowers anxiety level experienced by patients undergoing coronary angioplasty. Fifty nine patients were studied randomly assigned to receive regular at or no such therapy as an adjustment to standard care for 5 months. The primary outcome measure was anxiety at 2 .

\section{Sources of data}

\section{Design of Study}

The collection of data pertaining to anxiety levels of the Korfball players pre-during and post of the competition among the intercollegiate players who represented S.G.B. Amravati University.

${ }^{3}$ P.K. Radha "Psychological factors and Soccer performance of South Indian University Players" Sovenire First International and sixth National Conference of Sport Psychology (February 1991), p. 17

${ }^{4}$ C. Parthiban, "Selected Psychological factors as determinants for the basketball performance" (M.Phil Dissertation, Alagappa University, 1992)

${ }^{5}$ Kanji (2003), Autogenic training reduces anxiety after the coronary angioplasty. A randomized clinical trial. Retrieved Dec. 27, 2008 from http/www.eric.com.in 


\section{Selection of subject :}

The subjects were selected sample random method for the present study in the following manner.

1. 30 male subjects were selected from the intercollegiate Korfball players for the present study.

Selection of variables :

For the present study only the anxiety level of the subjects was investigated.

\section{Selection of test}

To collect data pertaining to the study, (SCAT) sport competitive Anxiety Test was applied.

Sampling procedure :

Simple Random Sampling Method was applied for the present study.

\section{Administration of test}

To collect data on the selected subject, (SCAT) questionnaire was administered on the selected subjects pre-during and post competition. Before distribution of the questionnaire the purpose of the study was explained to the subjects so that the subjects would be honest in their answers.

\section{Collection of data}

The answers and replies to the questionnaire that were distributed to the subject were recorded in a systematic way for further tabulation. The answersheet were collected and recorded with the help of key. Thus the raw score was recorded in each answersheet.

\section{Analysis of data :}

\section{Analysis and Interpretation of Data}

The data obtained from the responses given in the questionnaire which was marked according the key was analyzed by using one way analysis of variance Statistical Technique (ANOVA) to find out Anxiety level of Korfball players pre-during and post of the competition.

\section{Findings :}

The data were collected on 30 players of Korfball in which they were selected randomly as subjects. The statistical result of the anxiety level of Korfball pre-during post of competition was illustrated in the following table.

Table -1

Comparison of Means of Anxiety Level among the Korfball players Pre During and Post competition

\begin{tabular}{|c|c|c|c|c|}
\hline $\begin{array}{c}\text { Source of Variance } \\
(\mathrm{df})\end{array}$ & $\begin{array}{c}\text { Degree of } \\
\text { freedom (df) }\end{array}$ & $\begin{array}{c}\text { Sum of squares } \\
(\mathrm{ss})\end{array}$ & $\begin{array}{c}\text { Mean of squares } \\
\text { (MSS) }\end{array}$ & F-ratio \\
\hline $\begin{array}{c}\text { Between the } \\
\text { group }\end{array}$ & $\begin{array}{c}\mathrm{K}-1 \\
3-1=2\end{array}$ & 342.77 & 171.39 & $234.7^{*}$ \\
\hline Within the group & $\begin{array}{c}\mathrm{N}-\mathrm{K} \\
90-3=87\end{array}$ & 63.87 & $0.73\left(\mathrm{~S} \Delta \mathrm{W}^{2}\right)$ & \\
\hline
\end{tabular}

Significant level at 0.05 level.

Tabulated $\mathrm{F}_{0.05}=0.90$

The findings of Table-1 reveal that the means of anxiety level among the Korfball player differs significantly as the mean difference value is between pre competition and during competition $(\mathrm{DM}=$ 3.34), pre competition and post competition ( $\mathrm{DM}=1.36)$ and during competition and post competition $(\mathrm{DM}=1.36)$ are greater than the critical difference value of 0.043 . The difference of means are graphically depicted in fig. 1

Table No. 2

Paired Mean difference of Anxiety level of Korfball players pre-during and post competition

\begin{tabular}{|c|c|c|c|c|}
\hline Pre & During & Post & Mean difference & Critical difference \\
\hline 20.7 & 17.36 & & $3.34^{*}$ & 0.43 \\
\hline 20.7 & & 16 & $4.7^{*}$ & 0.43 \\
\hline & 17.36 & 16 & $1.36^{*}$ & 0.43 \\
\hline
\end{tabular}

* Significant at 0.05 of confidence.

Table value ' $F$ ' at 0.05 level of significance at 28 degree of freedom is 3.103 . The obtained ' $F$ ' value is less than the table value. Hence null hypothesis is accepted. Therefore there was no significance difference between the pre-during-post of competition. 


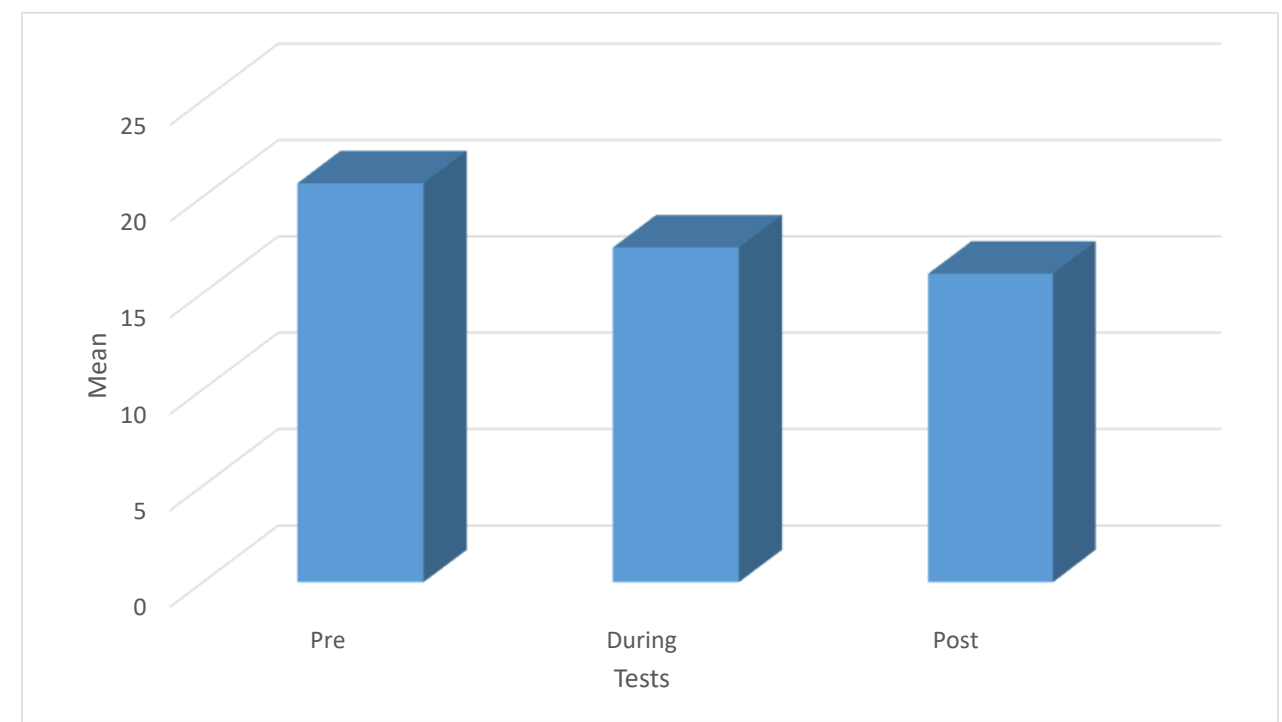

Figure 1

Means of Anxiety level of Korfball players pre, during and post competition

\section{Discussion of findings :}

It has been seen that a moderate level of Anxiety is best of the acquisition and performance of motor skill. Level of anxiety either too high or low tends to decrease the performance of a player. Anxiety is natural post of the competition in a player or Athlete.

Table 1, it clearly shows that there is a significant level of difference in anxiety level of a player while Pre-During and Post of the competition. During the three phase of competition it has been seen that anxiety level during the pre competition was compared by high in compare to During and Post of the competition.

The reason behind the high level of anxiety during the pre competition might be the various conditions of a player such as Mental stress, Environmental stress, Demanding for good performance. All these factor tends to decrease the metabolism reaction of the body which reduces the energy in the body. So due to this factors he finds himself uncomfortable and could not adjust to himself in the pre phase. But in case of during competition the players comes to an experience phase so the anxiety level during competition is low because the player adapts to the game structure, mode of self realization, confidence, positive attitude and motivation through coach and players. All these factors make anxiety level how in this phase.

After this two phases the anxiety level comes to certain resting level due to mainly a result, relaxation, performance level, certain level of anxiety is still seen regarding the performance in future, performance level, under level performance. As anxiety level differs in every game due to its nature of playing. Anxiety level could made be control by movement analyzing of the player through proper guiding experiencing the situation in which he is completely distriburb state of mind practicing the skill meditative exercise motivation. Thus these were finding and measures.

\section{Discussion of Hypothesis}

On the beginning of the study it was hypothesized that there may be significant difference of anxiety level. The finding of the study have revealed a significant difference of anxiety level pre-during and post competition.

\section{Conclusion}

On the basis of the findings of this study it is found that. The result of the study indicated that there was a significant difference in the anxiety level of Korfball players pre-during and post of competition.

\section{References}

1. P.K. Radha "Psychological factors and Soccer performance of South Indian University Players" Sovenire First International and sixth National Conference of Sport Psychology (February 1991), p. 17

2. C. Parthiban, "Selected Psychological factors as determinants for the basketball performance" (M.Phil Dissertation, Alagappa University, 1992)

3. Kanji (2003), Autogenic training reduces anxiety after the coronary angioplasty. A randomized clinical trial. Retrieved Dec. 27, 2008 from http/www.eric.com.in 